\title{
Dragoljub Jovičić*
}

\section{DUŽINA MARKETING KANALA PRI PLASMANU GASNIH KOTLOVA}

Sažetak: U zavisnosti od broja institucija koje učestvuju u konkretnom marketing kanalu, odnosno u zavisnosti od broja članova kanala, u stručnoj literaturi obično se marketing kanali klasifkuju na direktne i indirektne. Postoji i treći modalitet, koji se povremeno javlja u privrednoj praksi, koji predstavlja miks marketing tokova karakteristićnih za osnovna dva modela $i$ naziva se kvazidirektni marketing kanal. Ovaj model kanala obicno se javlja pri plasmanu proizvodnih dobara, ili kako se to takode veoma često kaže u „industrijskom marketingu”. Pri plasmanu gasnih kotlova na srpskom tržištu vrlo često, pogotovo kada su u pitanju veće količine, upravo se primenjuju kvazidirektni marketing kanali zbog svoje podobnosti, brže i efikasnije distribucije, i znatno nižih troškova prevoza i skladistenja.

Ključne reči: direktni, indirektni i kvazidirektni marketing kanali, marketing tokovi, plasman gasnih kotlova.

\section{LENGTH OF MARKETING CHANNELS IN SALES OF GAS BOILERS}

Abstract: Depending on the number of institutions participating in this marketing channel and depending on the number of channel members, the literature usually classifies marketing channels into direct and indirect. There is also the third modality, which occasionally occurs in commercial practice, representing a mix of marketing flows characteristic of the two basic models, called the quasi-direct marketing channel. This channel model usually occurs during the placement of production goods, or as it is also often said in the "industrial marketing." When the placement of gas boilers in Serbian market is concerned quasi-direct marketing channels are applied very often, especially when it comes to large quantities because of their suitability, faster and more efficient distribution, and significantly lower transport and storage costs.

Key words: direct, indirect and quasi-direct marketing channels, marketing flows, sales of gas boilers.

\section{UVOD}

Pri plasmanu gasnih kotlova na srpskom tržištu učestvuje veći broj institucija, pre svih posredničke organizacije, koje uvoze gasne kotlove direktno od inoproizvođača, ili ih

\footnotetext{
* Dr Dragoljub Jovičić, profesor strukovnih studija, Visoka poslovna škola strukovnih studija, Novi Sad, Srbija, e-mail: djovicic@uns.ac.rs, d.jovicic@sbb.rs.
} 
kupuju od njihovih predstavništava koja egzistiraju na teritoriji Republike Srbije. S obzirom na to da ne postoji ni jedan respektabilan domaći proizvođač gasnih kotlova, koji u kontinuitetu proizvodi kvalitetne aparate, snažniji domaći posrednici su pri nabavci usmereni na renomirane evropske proizvođače, kao što su: Vaillant, Bosch, Buderus, Remexa, Viessmann, Baxi i dr. ${ }^{1}$ Nakon uvoza gasnih kotlova veliki domaći distributeri preuzimaju ulogu lidera u marketing kanalima na domaćem tržištu. Zahvaljujući svojoj dominantnoj poziciji upravo oni kreiraju strukture kanala prodaje gasnih kotlova, biraju učesnike kanala (institucije), formiraju cene, određuju rabate i druge uslove prodaje.

Ključni ciljni segmenti ka kojima su usmerene aktivnosti uvoznika, odnosno snažnih domaćih posredničkih kompanija, pri daljoj distribuciji gasnih kotlova su: trgovine, investitori i instalateri. Svaki od ovih segmenata iziskuje poseban, sofisticiran pristup, koji će rezultirati različitim marketing strategijama snažnih posrednika, a koje će biti prilagođene konkretnim ciljnim segmentima i konkretnim članovima marketing kanala. Dakle, uvoznike, snažne domaće posrednike koji su preuzeli ulogu lidera u marketing kanalima gasnih kotlova, čekaju veoma kompleksni zadaci pri kreiranju marketing strategije, počevši od istraživanja tržišta, kreiranja optimalne dužine marketing kanala, izbora najkvalifikovanijih članova kanala, određivanja uslova prodaje, rabatne politike i sl., a sve sa ciljem da se formira efikasan kanal, ostvari puna satisfakcija krajnjih korisnika, ali isto tako i profitabilno poslovanje, pri čemu treba voditi računa i da svaki član kanala ima dovoljno prostora da ostvari svoju individualnu profitabilnost. ${ }^{2}$

\section{MODALITETI MARKETING KANALA U ZAVISNOSTI OD BROJA ČLANOVA KANALA}

Već je istaknuto da se u zavisnosti od broja članova marketing kanala - koji učestvuju u proizvodnji i distribuciji proizvoda do krajnjih korisnikai/ili potrošača, kanali dele na direktne, indirektne i kvazidirektne. Da li će to kretanje, odnosno da li će put robe od proizvođača do krajnjeg korisnika biti duži ili kraći zavisi od niza faktora, kao što su: karakteristike proizvoda, karakteristike konkurencije, kupaca, zatim u dobroj meri u zavisnosti od karakteristika samog proizvođača, kao i posrednika, zakonske regulative i niza drugih faktora.

Kada su u pitanju marketing kanali gasnih kotlova, s obzirom na kretanje, odvijanje pojedinih tokova između učesnika u kanalu (informativni, robni, vlasnički, tok plaćanja i tok rizika), nije baš uvek jednostavno odrediti da li se radi o direktnom ili indirektnom kanalu distribucije. Vrlo često se u praksi, prilikom plasmana gasnih kotlova, javljaju situacije kada pojedini marketing tokovi imaju nešto drugačiju putanju nego što to podela na direktne i indirektne marketing kanale predviđa, a što će se u nastavku rada podrobnije analizirati.

\footnotetext{
${ }^{1}$ www.vaillant.rs, www.baxi.co.uk, www.bosch-climate.rs, www.buderus.com, www.remeha.com, www. viesssmann.rs.

${ }^{2}$ Lovreta, Petković (2002: 293).
} 
Direktni marketing kanali se znatno više koriste prilikom prodaje proizvodnih dobara, nego što je to slučaj sa potrošnim dobrima namenjenim individualnoj ili porodičnoj upotrebi. Takođe, globalno sagledavajući tržište roba i usluga, može se zaključiti da dužina kanala ima tendenciju da bude kraća za usluge nego za proizvode. ${ }^{3}$

Posmatrajući samo proizvodna dobra, s obzirom na njihov izuzetno veliki broj, različitu vrednost i svrhu upotrebe, kao i niz drugih karakteristika po kojima se razlikuju, uočava se potreba kako za direktnim kontaktom proizvođača sa krajnjim korisnicima, tako i za korišćenjem, uključivanjem posrednika, ali i još nekih tzv. pomoćnih institucija u marketing kanale. $^{4}$

Istražujući problematiku proizvodnje i plasmana gasnih kotlova, upravo se došlo do zaključka da je najcelishodnije paralelno koristiti i direktne i indirektne marketing kanale. Kada je reč o direktnoj prodaji krajnjem korisniku, može se reći da se proizvođači, ili bolje reći veliki domaći posrednici, odlučuju za nju da bi uspostavili, odnosno zadržali dobar (prisan) poslovni odnos sa značajnim, po obimu kupovine velikim kupcima.

Radi boljeg razumevanja direktnog marketing kanala gasnih kotlova, daje se prikaz (Slika 1) marketing tokova između proizvođača, tačnije rečeno uvoznika (ako se posmatra domaće tržište), i krajnjih korisnika gasnih kotlova.

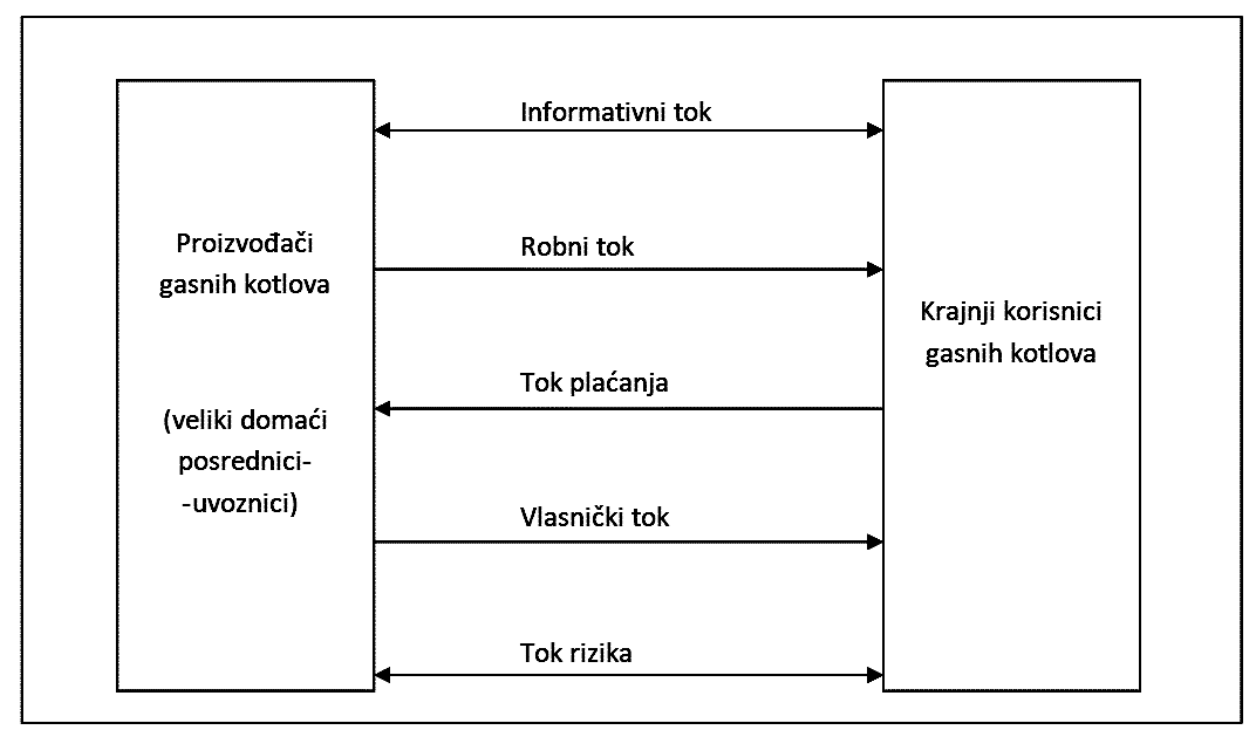

Slika 1. Marketing tokovi u direktnom marketing kanalu pri plasmanu gasnih kotlova

Izvor: Jovičić (2004: 67).

3 Kurtz, Clow (1998: 276).

4 Rosenbloom (1999: 71-72). 
S obzirom na to da je ranije već istaknuto da neki tokovi imaju jednosmerno a neki dvosmerno kretanje (što prikazuje strelice na Slici 1), sada se želi istaći nešto drugo, činjenica da se svi tokovi: informativni, robni, vlasnički, tok plaćanja i tok rizika odvijaju samo između ova dva učesnika u direktnom marketing kanalu, dakle između proizvođača (uvoznika) i krajnjeg korisnika. Znači, proizvođač, odnosno uvoznik, pri plasmanu gasnih kotlova informiše (putem promotivnih aktivnosti) krajnjeg korisnika, isporučuje mu robu, prenosi vlasništvo nad robom na njega i pri svemu tome snosi razne rizike. $S$ druge strane krajnji korisnik informiše uvoznika o svojim potrebama, vrši mu plaćanje po osnovu robe i takođe, za vreme svih tih aktivnosti, snosi potencijalne rizike, kao što su: mogućnost fizičkog uništenja robe, promena cene i sl.

Bez obzira na to što direktna prodaja krajnjim korisnicima i/ili potrošačima omogućava proizvođačima lakše i brže komuniciranje sa njima, držanje pod kontrolom svih aktivnosti u marketing kanalu, kao i eliminisanje troškova posrednika, u savremenoj tržišnoj privredi, zasnovanoj na podeli rada i sve većoj specijalizaciji, znatno je više proizvođača koji se odlučuju za korišćenje usluga posrednika - specijalizovanih prometnih institucija. Na taj način i pri plasmanu gasnih kotlova inoproizvođači koriste dobru tržišnu poziciju posrednika za plasman svojih proizvoda, odnosno koriste njegove mnogobrojne poslovne veze sa kupcima, smanjuju troškove sopstvene prodajne službe, a istovremeno redukuju troškove transporta i skladištenja.

Proizvođači pojedinih proizvodnih dobara, među njima i proizvođači gasnih kotlova, odnosno konkretnije na našem tržištu - uvoznici, koriste jednog ili više posrednika kada je tržišste fragmentirano i veoma disperzirano, kada je manja vrednost transakcija i kada kupci kupuju veći broj predmeta različitih marki u jednoj transakciji.

Radi lakše komparacije indirektnih marketing kanala sa direktnim, daće se prikaz marketing tokova između proizvođača, odnosno velikih i snažnih posrednika, koji se pojavljuju kao uvoznici gasnih kotlova, malih posrednika i krajnjih korisnika (Slika 2).

Značajno je navesti da promene u trgovini po svom intenzitetu i sadržaju znatno prevazilaze promene u sferi proizvodnje i finansija, tako da mnogi autori ističu da je u razvijenim tržišnim privredama u toku svojevrsna trgovinska revolucija. ${ }^{6} \mathrm{U}$ tom kontekstu treba veoma ozbiljno sagledati i ulogu tj. značaj trgovinskih (posredničkih) organizacija u marketing kanalima. Za razliku od direktnih marketing kanala, gde su se svi marketing tokovi (bez obzira da li su jednosmerni ili dvosmerni) odvijali između proizvođača (uvoznika) i krajnjih korisnika gasnih kotlova, kod indirektnih marketing kanala situacija je znatno drugačija. Robni (fizički) tok, tok plaćanja, vlasnički i tok rizika se odvijaju etapno, prvo na relaciji proizvođač (uvoznik) posrednik, a zatim na relaciji posrednik - krajnji korisnik. U slučaju da ima više posrednika u kanalu, onda se i između njih takođe uspostavljaju svi ovi tokovi. Dakle, krajnji korisnik nema dodirnih tačaka sa proizvođačem ni po jednom toku u okviru marketing kanala.

\footnotetext{
Milisavljević (2001: 336).

6 Lovreta, Končar, Petković (2005: 461).
} 
Izuzetak donekle predstavlja samo informativni tok, koji se paralelno odvija na relacijama proizvođač (uvoznik) - posrednik, posrednik - krajnji korisnik, kao i direktno proizvođač (uvoznik) - krajnji korisnik, omogućavajući protok, razmenu informacija u oba smera. $\mathrm{Na}$ taj način posrednik rasterećuje proizvođače, odnosno uvoznike, te preuzima na sebe obavezu izvršenja svih marketing tokova prema potrošačima, odnosno krajnjim korisnicima, naravno sa izuzetkom informativnog toka, ali ne u potpunosti, već samo delimično, jer je i sam posrednik direktno povezan sa krajnjim korisnikom dvosmernim informativnim tokom.

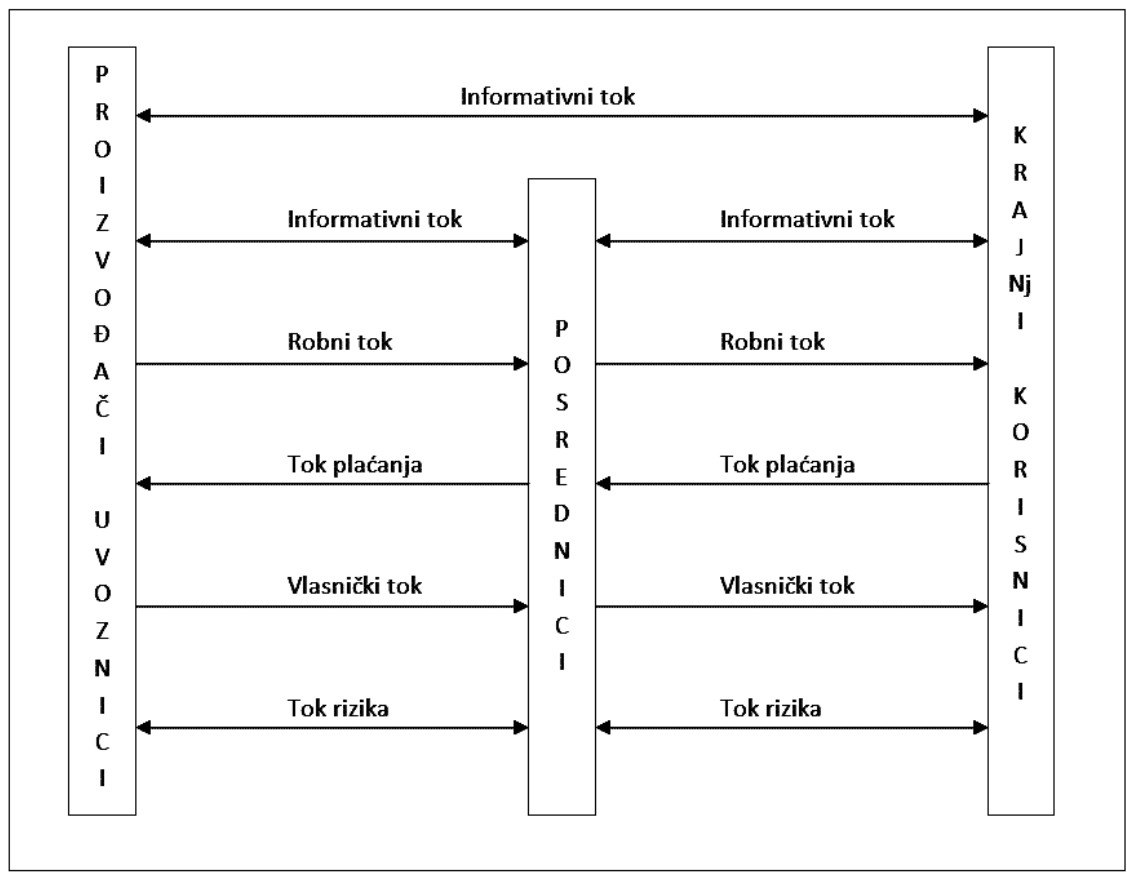

Slika 2. Marketing tokovi u indirektnom marketing kanalu pri plasmanu gasnih kotlova

Izvor: Jovičić (2004: 70).

Pored korišćenja direktnih marketing kanala, gde ostvaruju neposredan kontakt sa krajnjim korisnicima gasnih kotlova, kao i indirektnih, gde preko jednog ili više posrednika plasiraju svoje proizvode krajnjim korisnicima, proizvođači gasnih kotlova, odnosno na našem domaćem tržištu uvoznici gasnih kotlova, vrlo često koriste određeni modalitet marketing kanala, koji se prema kretanju marketing tokova između članova kanala ne može svrstati u direktne, ali ni u indirektne. Na Slici 3 upravo se daje takav primer, koji se inače veoma često javlja pri plasiranju gasnih kotlova, to su takozvani tranzitni poslovi. Pod tranzitnom trgovinom $^{7}$ podrazumeva se kupovina robe u jednoj, a prodaja u drugoj zemlji, s tim što ona

\footnotetext{
Milisavljević (1977: 313).
} 
(roba) ne prelazi granicu zemlje posrednika i prodaje se u nepromenjenom obliku (nema dorade). U unutrašnjoj trgovini takođe se odomaćio termin „tranzitni posao", pod kojim se podrazumeva posredovanje u prometu robe, $s$ tim da roba ne ide u skladište posrednika, već direktno kod proizvođača, odnosno uvoznika gasnih kotlova, ka krajnjem korisniku, naravno u nepromenjenom obliku - bez ikakvih dorada, prepakivanja i sl.

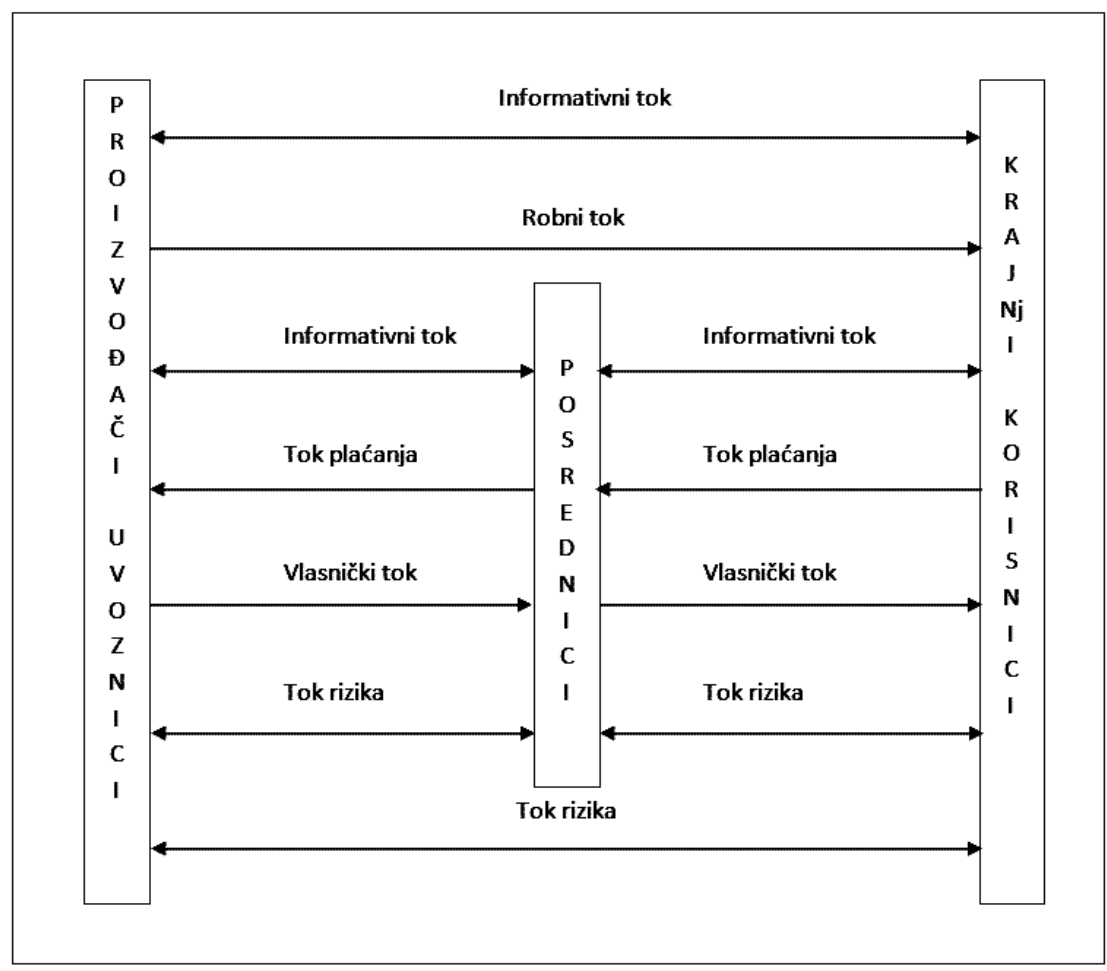

Slika 3. Marketing tokovi u kvazidirektnom marketing kanalu pri plasmanu gasnih kotlova

Izvor: Jovičić (2004:72).

Dobra strana tranzitnih poslova u unutrašnjem prometu gasnih kotlova, zbog čega se oni vrlo često i koriste, ogleda se u: smanjenju posredničkih - trgovačkih troškova (tranzitna marža je znatno niža od lagerske); smanjenju transportnih troškova (roba se od proizvođača (uvoznika) ne prevozi do posrednika, već direktno ide krajnjem korisniku); ubrzava se promet (jer se ne gubi vreme na prevoz i skladišstenje robe kod posrednika).

Bez obzira na sve ove uštede koje se postižu nabavkom robe u tranzitu, postoji i određeni limit kod tranzitnih poslova, a to je da se u tranzitu „odrađuju” obično samo „ozbiljnije” 
količine gasnih kotlova, sa većim finansijskim iznosima po transakciji, jer bi u suprotnom došlo do enormnog povećanja transportnih troškova po jedinici proizvoda.

Posmatrajući Sliku 3, može se odmah uočiti veća kompleksnost marketing tokova u kvazidirektnim marketing kanalima u odnosu na direktne i indirektne, kod kojih se svi marketing tokovi (sa delimičnim izuzetkom informativnog toka) uvek odvijaju između dva učesnika u kanalu. Kod direktne prodaje svi tokovi se obavljaju između proizvođača, odnosno uvoznika - velikog i snažnog posrednika, i krajnjeg korisnika, slično je i kod indirektne prodaje, $s$ tim što se tokovi odvijaju etapno, prvo na relaciji proizvođač (uvoznik) - posrednik, eventualno posrednik - posrednik i na kraju posrednik - krajnji korisnik gasnih kotlova. Kod kvazidirektnih marketing kanala kretanje marketing tokova je znatno složenije, robni (fizički) tok se obavlja direktno između proizvođača (uvoznika) i krajnjeg korisnika, tok plaćanja i vlasnički tok se obavljaju na relacijama proizvođač (uvoznik) - posrednik i posrednik - krajnji korisnik, dok se informativni tok i tok rizika paralelno odvijaju između proizvođača (uvoznika) i krajnjeg korisnika direktno, kao i na relacijama proizvođač (uvoznik) - posrednik i posrednik - krajnji korisnik.

Prateći samo robni tok koji ide direktno od proizvođača, odnosno uvoznika gasnih kotlova, do krajnjeg korisnika u tranzitnom poslovanju, moglo bi se reći da je reč o direktnom marketing kanalu, međutim, posmatrajući tokove plaćanja i vlasništva koji se odvijaju preko posrednika,jedanput na relaciji proizvođač (uvoznik) - posrednik, a drugi put posrednik - krajnji korisnik, moglo bi se isto tako konstatovati da je to indirektan kanal marketinga. Informativni tok ima identično kretanje kao kod indirektnih marketing kanala, dok tok rizika poprima složeniju formu kod kvazidirektnih kanala, $s$ obzirom na to da se po pitanju robnog toka rizik nalazi na relaciji proizvođač (uvoznik) - krajnji korisnik, dok se po osnovu tokova plaćanja i vlasništva rizik deli na relacijama proizvođač (uvoznik) - posrednik i posrednik - krajnji korisnik.

Kvazidirektni marketing kanal se često koristi u postojećim uslovima privređivanja, vrlo je oportun, jer putem njega krajnji korisnici gasnih kotlova nabavljaju potrebne proizvode jeftinije (niže su trgovačke marže i troškovi transporta), dok posrednici ostvaruju nešto manju stopu provizije, ali zato potpuno eliminišu troškove prevoza, istovara i skladištenja robe.

\section{KREIRANJE OPTIMALNE DUŽINE MARKETING KANALA PRI PLASMANU GASNIH KOTLOVA}

Imajući u vidu sve napred navedeno o karakteristikama direktnih, indirektnih i kvazidirektnih (virtuelnih direktnih) marketing kanala, može se zaključiti da domaći lideri marketing kanala gasnih kotlova, a to su u principu uvoznici, koriste sva tri modela. Jedan deo prometa obave putem direktnih kanala, uspostavljajući direktnu poslovnu komunikaciju 
sa investitorima značajnijih komercijalnih ili rezidencijalnih objekata, dok drugi, može se reći veći deo plasmana obavljaju putem indirektnih ili kvazidirektnih (virtuelnih) marketing kanala, putem jednog ili više posrednika, tako da faktički uvoznici sa krajnjim korisnicima ne ostvaruju direktnu poslovnu komunikaciju. ${ }^{8}$

U principu proizvođači i/ili uvoznici proizvodnih dobara u zavisnosti od vrste proizvoda obično kombinuju direktnu i indirektnu prodaju, dok proizvođači, odnosno uvoznici potrošnih dobara, u principu koriste duže marketing kanale, tj. za plasman svojih proizvoda u velikoj meri koriste usluge posredničkih organizacija. Da li će se proizvođači (uvoznici) odlučiti za direktan kontakt sa potrošačima ili će to prepustiti posredniku, u dobroj meri zavisi od postojeće strategije proizvoda, cena i promocije, mada treba imati $\mathrm{u}$ vidu i povratnu spregu, tj. da doneta odluka o izabranom marketing kanalu ima znatan uticaj na buduću politiku proizvoda, cena i promocije. U zavisnosti od broja učesnika u marketing kanalu, prema Kotleru', može se govoriti o broju nivoa u kanalu. Svaki učesnik koji svojim aktivnostima doprinosi približavanju proizvoda i njegovog vlasništva krajnjem kupcu predstavlja jedan nivo u kanalu. Uzimajući u obzir činjenicu da proizvođač i krajni korisnici predstavljaju početnu i završnu kariku u marketing kanalu, te da bez jednog od njih marketing kanal ne može ni egzistirati, samo njihovo učešće - bez ijednog posrednika, naziva se kanalom nultog nivoa. Učestvovanjem samo jednog posrednika između njih dobija se kanal prvog nivoa, uključivanjem još jednog člana kanala formira se kanal u dva nivoa. Naravno, postoje kanali sa tri i više nivoa, ali se oni znatno ređe javljaju u praksi.

Inače, obično se marketing kanal definiše kao set međusobno zavisnih organizacija koje su uključene u proces stvaranja proizvoda ili usluga i dostupnosti, raspoloživosti proizvoda i usluga za korišćenje ili potrošnju. ${ }^{10}$ Dakle, marketing kanali - da bi uspešno obavili svoj zadatak, treba da obezbede dobar asortiman proizvoda, te da ga na vreme, u formi pogodnoj za upotrebu, na pravom mestu i po ceni koju su spremni da plate, ponude kupcima, odnosno krajnjim korisnicima.

Može se reći da direktni marketing kanali za proizvođače gasnih kotlova, u odnosu na indirektne, imaju određene prednosti koje se ogledaju u mogućnosti kontrole celokupnog sistema distribucije, vođenju samostalne marketing politike, bržem dolaženju do informacija o potrebama krajnjih korisnika, kao i eliminisanju troškova vezanih za cenu rada posrednika. Međutim, postoje i neke slabosti, a to je da proizvođač ne može sam tako uspešno da obavlja sve one funkcije koje inače vrše posrednici, kao i to da se veoma povećavaju finansijski izdaci vezani za osposobljavanje i rad sopstvene prodajne službe, te da bi za proizvođače bilo celishodnije da ulože ta sredstva u osnovnu (proizvodnu) delatnost, gde bi verovatno ostvarili veći profit. Dakle, postoji niz razloga da se proizvođač opredeli za korišćenje usluga posrednika, ali isto tako postoji

\footnotetext{
8 Jovičić, Salai (2011: 135-145).

${ }^{9}$ Kotler (1999: 641).

${ }^{10}$ Coughlan, Anderson, Stern, El-Ansary (2001: 3).
} 
i argumentacija da se odluči za direktnu prodaju svojim krajnjim korisnicima. Značaj posrednika u marketing kanalu može se vrlo slikovito objasniti i preko neusklađenosti asortimana proizvedenih i asortimana traženih roba na tržištu. Najčešće velika većina proizvođača proizvodi ograničen broj proizvoda u veoma velikim količinama, dok $s$ druge strane krajnji korisnici traže prilično širok asortiman proizvoda i to u vrlo malim količinama, zato je u takvim slučajevima uloga posrednika od izuzetnog značaja, inače bi bez njih došlo do ozbiljnog zastoja u protoku roba na tržištu. Bez obzira na to da li je marketing kanal direktan (nulti nivo) ili u svojoj strukturi osim proizvođača i krajnjeg korisnika ima još učesnika (posrednika), njegova osnovna uloga je da omogući da roba od proizvođača dođe do potrošača i/ili krajnjeg korisnika na vreme, na mesto i u formi pogodnoj za upotrebu.

Vodeći računa o efikasnosti marketing kanala, obično inoproizvođači i/ili domaći uvoznici gasnih kotlova, tj. lideri marketing kanala, preferiraju one kanale koji će omogućiti punu satisfakciju krajnjih korisnika, ali i rentabilno poslovanje, odnosno profitabilnost članova kanala. U tom kontekstu, da bi izbegli rizik izbora neefikasnih marketing kanala i izbor nedovoljno kvalifikovanih članova kanala, obično uvoznici gasnih kotlova praktikuju primenu nekog od modela za oblikovanje (kreiranje) marketing kanala. Po jednom od tih modela proces kreiranja marketing kanala sastoji se od osam međusobno zavisnih koraka. ${ }^{11}$ Polazi se od analize situacije u postojećem marketing kanalu; analize potreba ciljnih kupaca i krajnjih korisnika; zatim se prikupljaju informacije o relevantnim faktorima za izbor kanala (ekonomskim i sociopsihološkim); određuju se ciljevi koji se žele ostvariti konkretnim marketing kanalom; zatim se identifikuju alternativni kanali marketinga; vrši se rangiranje i izbor marketing kanala; identifikovanje, rangiranje i izbor članova kanala; najzad, vrši se implementacija, kontrola i modifikovanje marketing kanala.

Nakon primene navedenog, ili nekog drugog modela za kreiranje marketing kanala, sigurno je da će domaći lideri kanala za plasman gasnih kotlova značajno smanjiti rizik izbora neefikasnog kanala, i smanjiti rizik pri izboru nedovoljno kvalifikovanih članova kanala, ali je takođe neophodno da lideri kanala maksimalno uvažavaju i sve relevantne faktore iz okruženja, kao i sve specifičnosti konkretnog tržišnog segmenta, kako bi se kreirala optimalna struktura marketing kanala, koja će obezbediti punu satisfakciju krajnjih korisnika i profitabilnost svih članova marketing kanala.

\section{ZAKLJUČNA RAZMATRANJA}

Imajući u vidu sve napred navedeno o marketing kanalima, prvo kroz teorijsku prizmu: o dužini kanala, vrsti marketing tokova, kao i o institucijama koje čine kanalsku strukturu, ali uvažavajući i konkretne specifičnosti koje se odnose na realnu privrednu situaciju

$\overline{11}$ Jovičić (2004: 186-189). 
pri plasmanu gasnih kotlova na domaćem tržištu, može se uočiti da lideri kanala (veliki uvoznici) koriste sva tri modaliteta marketing kanala pri distribuciji gasnih kotlova.

U zavisnosti od konkretnih potreba i zahteva pojedinih tržišnih segmenata lideri kanala prilagođavaju svoj marketing miks, a u okviru njega, naravno, kreiraju i različite dužine svojih marketing kanala, kako bi što kvalitetnije i potpunije zadovoljili potrebe i želje svojih kupaca, odnosno krajnjih korisnika. U tom kontekstu, u zavisnosti od toga da li su njihove marketing aktivnosti usmerene ka trgovinskim organizacijama, investitorima, instalaterima, ili individualnim krajnjim korisnicima, lideri marketing kanala pri plasmanu gasnih kotlova kreiraju i koriste direktne, indirektne, ali po potrebi i kvazidirektne marketing kanale. U suštini, lideri kanala se odlučuju za onaj modalitet marketing kanala koji će im omogućiti da ostvare punu satisfakciju kupaca (krajnjih korisnika), ali i individualnu profitabilnost svih članova marketing kanala.

\section{LITERATURA}

[1] Coughlan, T. A., Anderson, E., Stern, W. L., El-Ansary, I. A., (2001) Marketing Channels, New Jersey, Prentice-Hall.

[2] Jovičić, D., (2004) Izbor marketing kanala proizvodnih dobara, doktorska disertacija, Novi Sad.

[3] Jovičić, D., Salai, S., (2011) Poslovno komuniciranje, Novi Sad, Visoka poslovna škola strukovnih studija.

[4] Kotler, P., (1999) Upravljanje marketingom: analiza, planiranje, primjena $i$ kontrola, Zagreb, Informator.

[5] Kurtz, L. D., Clow, E. K., (1998) Services Marketing, New York, John Wiley \& Sons.

[6] Lovreta, S., Končar, J., Petković, G., (2005) Kanali marketinga, Beograd, Centar za izdavačku delatnost Ekonomskog fakulteta u Beogradu.

[7] Lovreta, S., Petković, G., (2002) Trgovinski marketing, Beograd, Ekonomski fakultet Beograd.

[8] Milisavljević, M., (2001) Marketing, Beograd, Savremena administracija.

[9] Milisavljević, M., redaktor, (1977) Leksikon marketinga, Beograd, Savremena administracija.

[10] Rosenbloom, B., (1999) Marketing Channels, Orlando, The Dryden Press.

[11] www.baxi.co.uk. 
112 DUŽINA MARKETING KANALA PRI PLASMANU GASNIH KOTLOVA

[12] www.bosch-climate.rs.

[13] www.buderus.com.

[14] www.junkers.com.

[15] www.remeha.com.

[16] www.vaillant.rs.

[17] www.viesssmann.rs.

Primljeno: 28.12.2011.

Odobreno: 18.01.2012. 